\title{
Disaggregation of probabilistic ground motions in two cities of Western Iran, Kermanshah and Sanandaj
}

\author{
Elham Shabani ${ }^{\star}$, Noorbakhsh Mirzaei, Mehrdad Pakzad
}

Institute of Geophysics, University of Tehran, Tehran, Iran

\author{
Article history \\ Received April 23, 2013; accepted October 30, 2013. \\ Subject classification: \\ PSHA, Scenario earthquake, Disaggregation, Main Recent Fault, Zagros, Iran.
}

\begin{abstract}
This article presents the results of disaggregation of ground motion hazard obtained for two of Iran's urban centers, Kermanshah and Sanandaj. Disaggregation of peak ground acceleration (PGA) and spectral acceleration hazard corresponding to mean return periods of 475 and 50 years is performed. 12 area seismic sources in the study region as well as 15 area seismic sources in a 150-km distance from the region are delineated. The scenario earthquakes are characterized by bins of magnitude, $M$, source-to-site distance, $R$, and number of standard deviations, $\varepsilon$, that the ground-motion parameter is away from its median value for that $M-R$ pair as estimated by a prediction equation. In most cases, the sources closer to the site dominate. Larger, more distant earthquakes contribute more significantly to hazard for longer periods than for shorter periods. Disaggregation plots can provide useful information on the distance and magnitude of predominant sources, which can be used to generate scenario earthquakes and select corresponding time histories for seismic design.
\end{abstract}

\section{Introduction}

For many earthquake and/or geotechnical engineering analyses, time histories compatible with local seismic activity are desired. It is desirable the selection of these time histories to be based on a probabilistic seismic hazard assessment (PSHA) consistent with the seismicity of the region. PSHA aggregates ground motion contributions from all earthquakes of all possible magnitudes, as probability at all significant distances from the site of engineering interest. Therefore, the PSHA results are not representative of a single-design earthquake. For a given site of engineering interest, the disaggregation of the PSHA results provides a tool to understand the relative contribution of each source to the overall seismic hazard. Precisely, the disaggregation process extracts the combinations of magnitude (M), source-to-site distance $(\mathrm{R})$ and the number of standard deviations $(\varepsilon)$ by which a ground motion parameter differs from the median value predicted by a ground motion prediction equation (GMPE) given magnitude, $\mathrm{M}$, and distance, $\mathrm{R}$. The hazard disaggregation portrays the design or controlling earthquake from either the mean or modal values of $\mathrm{M}$ and $\mathrm{R}$ only, or $\varepsilon$ as well. The probabilistic disaggregation methodology is explicated in great detail on the studies of Chapman [1995], McGuire [1995], Cramer and Petersen [1996], Frankel et al. [1996], Bazzurro and Cornell [1999], Harmsen et al. [1999], Frankel et al. [2000], Harmsen and Frankel [2001], Campos Costa et al. [2002], Montilla et al. [2002], Harmsen et al. [2003], Barani et al. [2009], Sousa and Costa [2009], Chioccarelli and Iervolino [2013] and Sabetta [2013].

Based on the seismic hazard study conducted by Shabani and Mirzaei [2007], the hazard assessment results have been disaggregated in terms of magnitude, distance and epsilon, to investigate the scenario earthquake contributing the most to the ground motion hazard. The disaggregation was undertaken in accordance with the procedure recommended by McGuire [1995].

Shabani and Mirzaei [2007], assuming that earthquakes follow a Poisson model, used a probabilistic procedure to calculate seismic hazard for different return periods in the Kermanshah-Sanandaj region, an area encompassed by $46-48^{\circ} \mathrm{E}$ longitudes and $34-36^{\circ} \mathrm{N}$ latitudes. 12 seismic sources are delineated in the Kermanshah-Sanandaj region as well as 15 other seismic sources in a $150-\mathrm{km}$ distance from the region.

The major aim of this study is the disaggregation of seismic hazard for the two cities; Kermanshah and Sanandaj in the west of Iran. In this regard, the quan- 
tified hazard values in terms of the peak ground acceleration (PGA) over bedrock, following the national building code $\left(\mathrm{V}_{\mathrm{s} 30}>750 \mathrm{~m} / \mathrm{s}\right)$, are mapped for $10 \%$ and $63 \%$ probabilities of exceedance in 50 years on grid intervals of $0.1^{\circ}$, using the NGA model of Boore and Atkinson [2008] and the GMPE developed in Ambraseys et al. [1996]. Then, disaggregation of the hazard is done in terms of magnitude-distance pairs, and epsilon in each site of Kermanshah and Sanandaj.

\section{Tectonic setting}

Zagros continental collision zone is the most seismic active region of Iran. The Crushed Zone of Zagros, also known as High Zagros, consists of high mountains parallel to the Zagros fold and thrust belt. The Zagros Crushed Zone is bounding from north by the Main Zagros Reverse Fault and the Main Recent Fault (MRF) (Figure 1). Wellman [1966] identified the Main Recent Fault, based on the stream pattern. Later, Tchalenko and Braud [1974] presented a more detailed description of this conspicuous active structure. MRF makes the boundary between the High Zagros and the Sanandaj-Sirjan zones. From southwest to northeast,

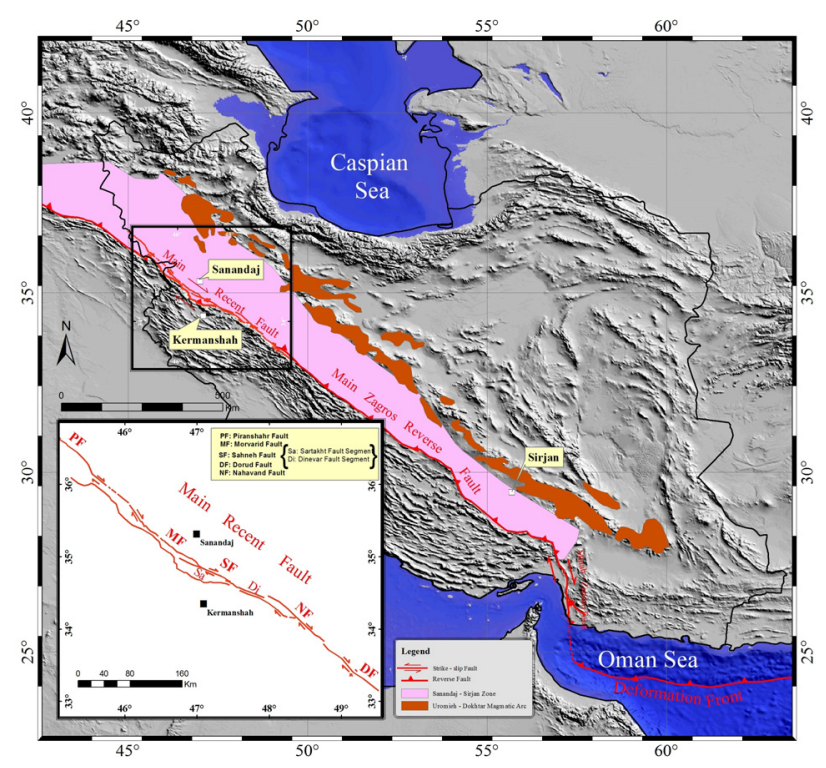

Figure 1. Zagros mountains annotated with Major fault systems, the Sanandaj-Sirjan zone. In set shows Main Recent Fault and the relevant fault segments.

rock units demonstrated higher grade of deformation that is maximized in the boundary zone where the thrust sheets verge southwardly. The MRF is a prominent right-lateral strike-slip fault system with a northwest-southeast trend in the northeast Zagros border zone. It is broadly parallel to, and younger than, the Main Zagros Reverse Fault (Figure 1). The MRF is a major seismogenic structure that comprises several segments (namely, the Dorud, Nahavand, Sahneh, Di- navar, Morvarid and Piranshahr faults) with different levels of seismicity (Figure 1). More intense seismic activity in Zagros is concentrated along the Main Recent Fault, between $33^{\circ} \mathrm{N}$ and $35^{\circ} \mathrm{N}$ on the Dorud, Nahavand, Dinavar and Sahneh segments, while the Morvarid and Piranshahr segments to the north show relative seismic quiescence [Tchalenko and Braud 1974, Berberian 1995, Shabani and Mirzaei 2007].

\section{Probabilistic seismic hazard analysis}

PSHA is a process that integrates aleatory uncertainties to calculate the mean annual rate of exceeding a given ground motion parameter value at a site. This approach is able to provide the estimate of ground motion with a specified confidence level (probability of not exceeding).

Traditionally, the configuration of individual seismic sources could be points, lines, areas or volumes, depending on the type of source chosen and the ability to define it in geologic space [Reiter 1990]. The point source model is used when there is no evidence to define a causative structure for the corresponding earthquakes. Line sources are modeled for identified active faults.

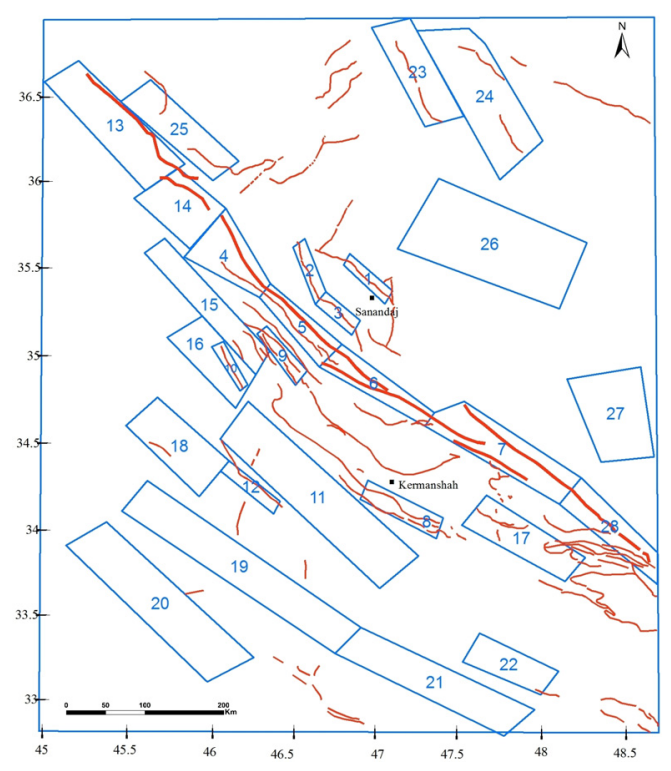

Figure 2. Potential seismic sources in the Kermanshah-Sanandaj region [Shabani and Mirzaei 2007].

Potential seismic source zones are determined using tectonic information of the region, epicenter distributions of earthquakes and other available geologi$\mathrm{cal} /$ geophysical information. Possible rupture segments may be reflected by structural discontinuities of the fault. For instance, where strike-slip fault intersect and offset the thrust is considered as a structural discontinuity. Changes in orientation of the fault, abrupt changes in dip, changes in net slip [Knuepfer 1989] and 


\begin{tabular}{|c|c|c|c|c|c|c|}
\hline \multirow[t]{2}{*}{ Source No. } & & & & & \multirow[t]{2}{*}{$M_{\max }$} & \multirow[t]{2}{*}{ Beta } \\
\hline & $5.5<\mathrm{M}<=6.0$ & $6.0<M<=6.5$ & $6.5<M<=7.0$ & $7.0<\mathrm{M}<=7.5$ & & \\
\hline 1 & 0.0004 & 0.0002 & & & 6.5 & 1.9 \\
\hline 2 & 0.0004 & 0.0002 & & & 6.5 & 1.9 \\
\hline 3 & 0.0004 & 0.0002 & & & 6.5 & 1.9 \\
\hline 4 & 0.026 & 0.003 & 0.001 & & 7.0 & 2.4 \\
\hline 5 & 0.010 & 0.003 & 0.001 & & 7.0 & 2.4 \\
\hline 6 & 0.011 & 0.003 & 0.001 & 0.006 & 7.5 & 2.4 \\
\hline 7 & 0.027 & 0.027 & 0.0222 & 0.006 & 7.5 & 2.4 \\
\hline 8 & 0.008 & 0.002 & & & 6.5 & 2.4 \\
\hline 9 & 0.009 & 0.003 & & & 6.5 & 2.4 \\
\hline 10 & 0.009 & 0.003 & 0.001 & & 6.5 & 2.4 \\
\hline 11 & 0.006 & 0.002 & & & 6.5 & 2.4 \\
\hline 12 & 0.007 & 0.002 & & & 6.5 & 2.4 \\
\hline 13 & 0.008 & 0.002 & & & 6.5 & 2.4 \\
\hline 14 & 0.008 & 0.002 & & & 6.5 & 2.4 \\
\hline 15 & 0.007 & 0.002 & & & 6.5 & 2.4 \\
\hline 16 & 0.007 & 0.002 & & & 6.5 & 2.4 \\
\hline 17 & 0.008 & 0.002 & & & 6.5 & 2.4 \\
\hline 18 & 0.040 & 0.002 & & & 6.5 & 2.4 \\
\hline 19 & 0.040 & 0.002 & & & 6.5 & 2.4 \\
\hline 20 & 0.039 & 0.025 & 0.011 & 0.0001 & 7.5 & 2.4 \\
\hline 21 & 0.007 & 0.002 & & & 6.5 & 2.4 \\
\hline 22 & 0.007 & 0.002 & & & 6.5 & 2.4 \\
\hline 23 & 0.002 & 0.0001 & & & 6.5 & 1.9 \\
\hline 24 & 0.002 & 0.0001 & & & 6.5 & 1.9 \\
\hline 25 & 0.0004 & 0.002 & & & 6.5 & 1.9 \\
\hline 26 & 0.0004 & 0.0001 & & & 6.5 & 1.9 \\
\hline 27 & 0.002 & 0.002 & 0.0001 & 0.0001 & 6.5 & 1.9 \\
\hline
\end{tabular}

Table 1. The seismic parameters of potential seismic sources of the study region and surrounding areas.

changes in spatial pattern of seismicity [Ye et al. 1995] also may be considered to recognize the structural discontinuities. In this study, potential seismic sources are modeled as area sources (Figure 2), in which configuration of each source zone is controlled, mainly, by the size of active faults, mechanism of earthquake faulting and the depth of the earth crust in which large earth- quakes originate [see Mirzaei et al. 1999]. Area sources assume that the rate of occurrence is uniform throughout. Therefore, every location within the area has equal probability that an event will occur. The maximum earthquake magnitude $\left(M_{\max }\right)$ for each seismic source is determined in two ways: the maximum historical earthquake approach or using the empirical relation- 


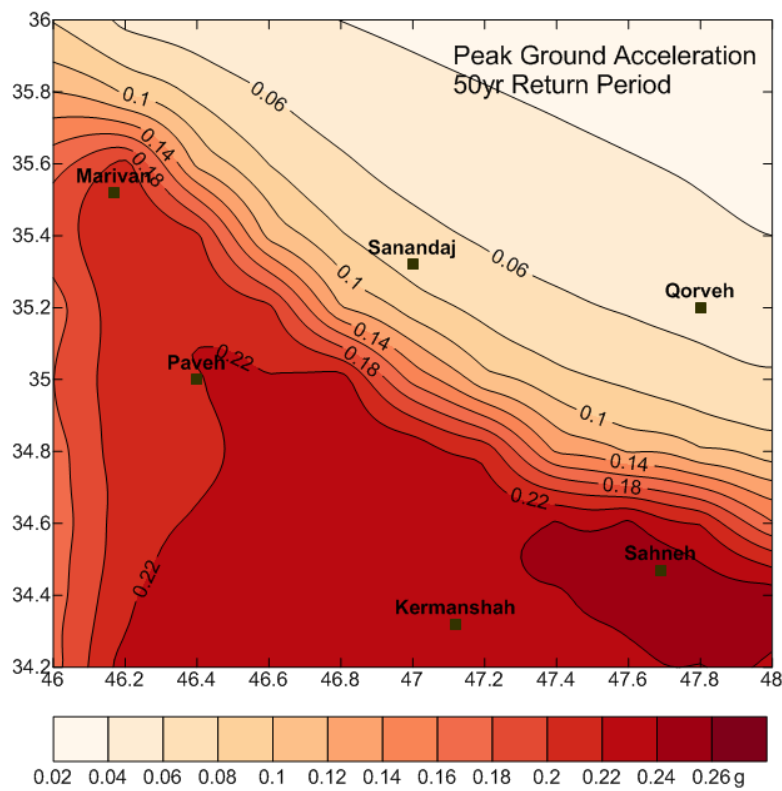

Figure 3. Seismic hazard map of the Kermanshah-Sanandaj region in terms of PGA for the 50-year return period.

ships proposed by Wells and Coppersmith [1994]. Estimated values of $M_{\max }$ in potential seismic sources range from 6.5 to 7.5 . Table 1 includes the potential seismic source characterization parameters, including

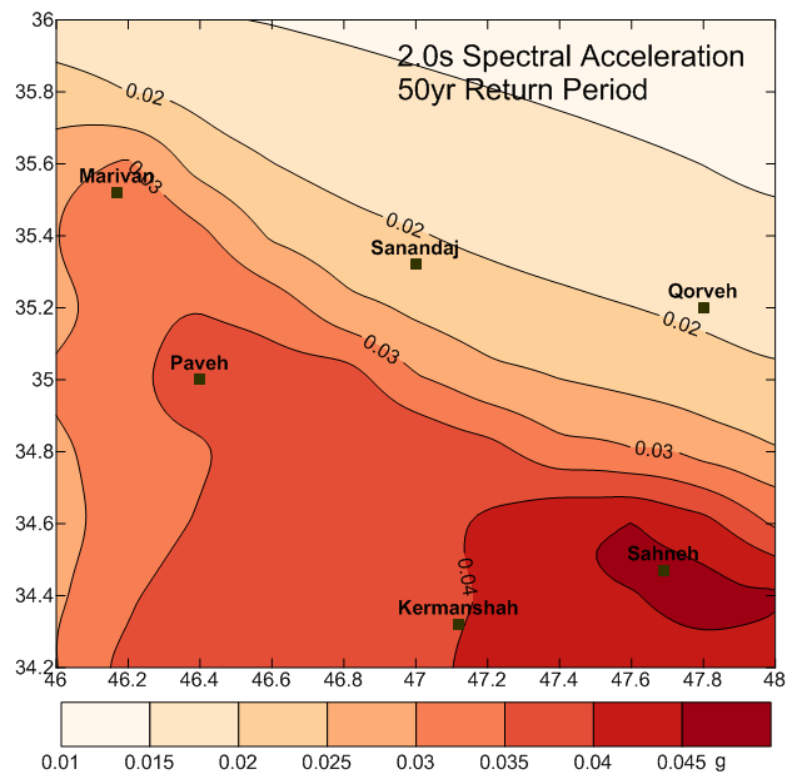

Figure 5. Seismic hazard map of the Kermanshah-Sanandaj region in terms of $\mathrm{Sa}(2.0 \mathrm{~s})$ for the 50 -year return period.

maximum magnitude and annual rates of occurrence in defined magnitude intervals for each potential seismic source. Because of the lake of data in each potential source, Beta values are allocated from the seismotectonic proviences. The minimum magnitude $\left(M_{\min }=4.0\right)$ is used to define the range of earthquakes used in hazard calculations. Earthquakes with magnitude $4.0 \leq \mathrm{M}<5.5$ are considered as background seis-

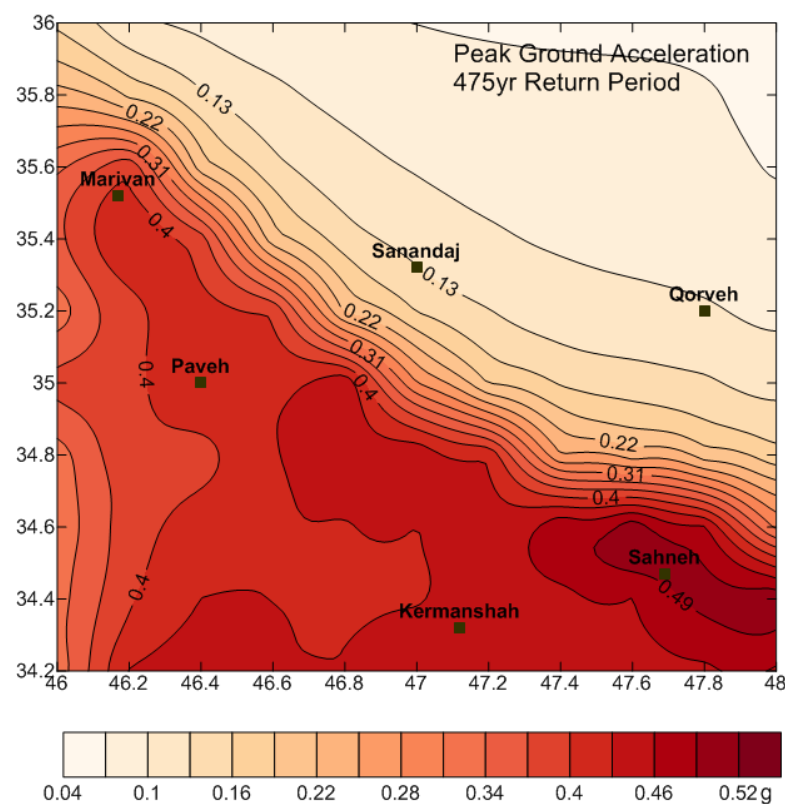

Figure 4. Seismic hazard map of the Kermanshah-Sanandaj region in terms of PGA for the 475-year return period.

mic activity. Since there is no systematic difference between $M_{s}$ and $M_{w}$ within the range of 5.7 to 8.0, all magnitude units are considered $\mathrm{M}_{\mathrm{s}}$. On the other hand in the range of 4.7 to $5.0, \mathrm{M}_{\mathrm{s}}$ is systematically smaller

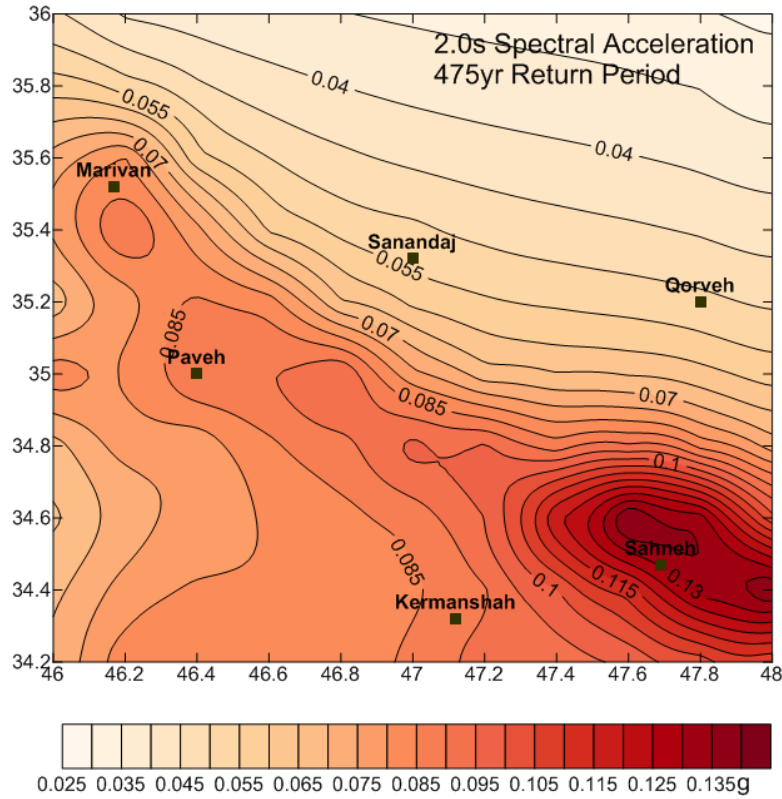

Figure 6. Seismic hazard map of the Kermanshah-Sanandaj region in terms of $\mathrm{Sa}(2.0 \mathrm{~s})$ for the 475 -year return period.

than $M_{w}$, the standard deviation of the difference between each pair of $\mathrm{M}_{\mathrm{s}}$ and $\mathrm{M}_{\mathrm{w}}$ is $\sim 0.19$ [Wells and Coppersmith 1994]. The annual mean occurrence rate of earthquakes in potential seismic sources is calculated by the concept of spatial distribution function (SDF) [Shi et al. 1992]. Based on SDF, the annual mean occurrence rate of earthquakes in a seismotectonic province should be allocated to each magnitude inter- 
val in the corresponding potential seismic sources in order to properly reflect the inhomogeneity of seismicity in time and space, and to avoid the underestimation of a potential hazard of large magnitude earthquakes. Different kinds of seismological, tectonic, and geophysical data can be used to indicate the possible future earthquake activities in the interest region, providing basis for evaluation of spatial distribution function. For more details, one can refer to Shabani and Mirzaei [2007]. In this study, four controlling factors [Shabani and Mirzaei 2007] are considered for evaluation of SDF: the reliability of delineation of potential seismic sources; tectonic setting of potential seismic sources; structural elements in potential seismic sources and characteristics of seismic activity in potential seismic sources. For calculation of spatial distribution function based on the controlling factors, the method of equal weight summation given by Yan [1993] is used.

In PSHA, aleatory uncertainties, which are inherently random, are accounted for by considering earthquake events with all possible magnitudes and distances. Epistemic uncertainty is that which is due to potential errors in the physical description of seismic-wave attenuation and associated source size [Harmsen et al. 1999]. It can be reduced with additional knowledge, information or data [Bozorgnia and Bertero 2004]. In this study, two GMPEs are employed to model epistemic uncertainty. The two attenuation relations, developed in Ambraseys et al. [1996] and Boore and Atkinson [2008], are given equal weights in the determination of the conditional probability that response spectral acceleration or peak ground motion acceleration exceeds some reference ground motion, given the occurrence of an earthquake for sites of the Kermanshah and Sanandaj. There are very few GMPEs appropriate for the study region in Zagros. Shoja-Taheri et al. [2010] carried out a comprehensive study on comparison of three Next Generation Attenuation (NGA) equations [Boore and Atkinson 2008, Campbell and Bozorgnia 2008, Chiou and Youngs 2008] as representatives of all the NGA models, with the strong-motion data recorded in Iran, and concluded that the three NGA models are generally applicable to the presently available Iranian dataset. Shoja-Taheri et al. [2010] also approved that the NGA model of Boore and Atkinson [2008] is somewhat more applicable for Iran than the other two models, since some of the details on the near source effects in it (e.g., effects of hanging wall and footwall, distance of the upper part of the fault rupture to the surface, and so on) are excluded. The GMPE developed in Ambraseys et al. [1996] is employed which uses a large and uniform dataset to find absolute spectral acceleration ordinates in Europe and Middle East. This equation used in the range of magnitudes from $\mathrm{M}_{\mathrm{s}} 4.0$ to 7.5 and for source-to-site distances of up to $200 \mathrm{~km}$.

Ground motion parameters PGA and $\mathrm{Sa}(\mathrm{T})$ are calculated, where PGA is the peak horizontal ground acceleration and $\mathrm{Sa}(\mathrm{T})$ represents the $5 \%$ damped spectral acceleration for period $\mathrm{T}$ in seconds. We considered PGA to be part of the acceleration response spectrum with a period of $0.01 \mathrm{sec}$, because most of the NGA models [Campbell and Bozorgnia 2008, Chiou and Youngs 2008, Idriss 2008] have identical coefficients for PGA and Sa $(0.01 \mathrm{sec})$. Idriss [2008] notes that the observed values of PGA and $\mathrm{Sa}(0.01 \mathrm{sec})$ are generally within $2 \%$ of each other. Figures 3 to 6 show the hazard maps in terms of PGA and 2.0s spectral acceleration, representing the mean acceleration values for the 475 and 50-year return periods. Hazard calculations were carried out using the EZ-FRISK (version 7.43) code [Risk Engineering 2010].

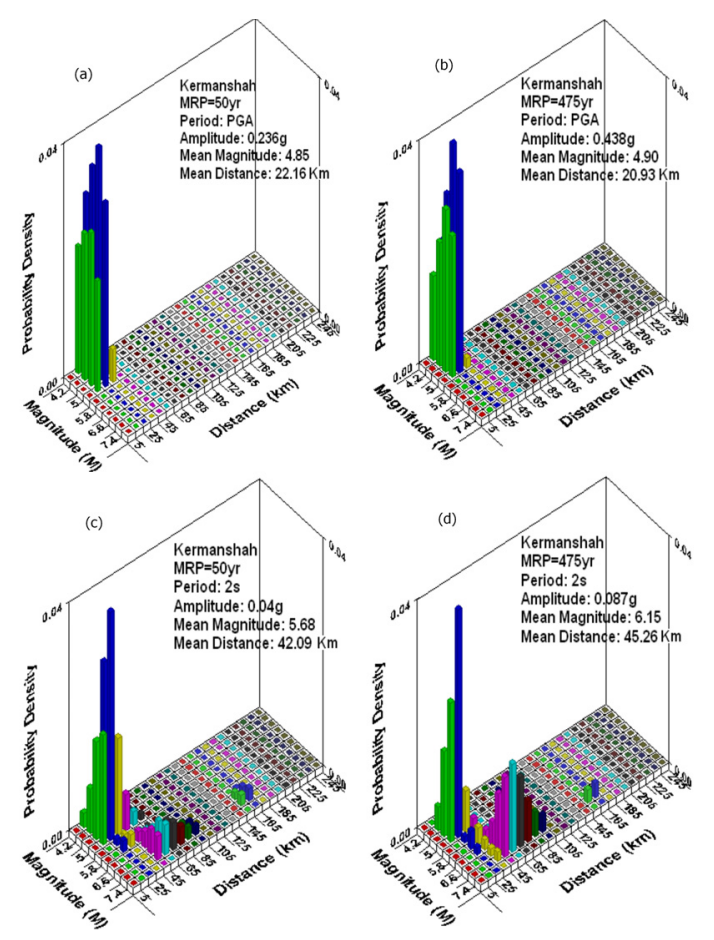

Figure 7. Disaggregated seismic hazard for a site in Kermanshah for $63 \%$ and $10 \%$ in 50 years probability of exceedances for PGA and $\mathrm{Sa}(0.2 \mathrm{~s})$. Bins of width 0.4 in magnitude, $10 \mathrm{~km}$ in distance, and 0.2 in $\varepsilon$ are used.

\section{Disaggregating seismic hazard}

The representation of the hazard at a site provided by the disaggregation procedure takes a step back from the probabilistically framed final outcomes and displays the hazard in terms of the readily understandable parameters. When the hazard is disaggregated the result is a suite of magnitude-distance pairs that occur with various probabilities. The identification of the most critical earthquake scenarios is therefore made relatively 


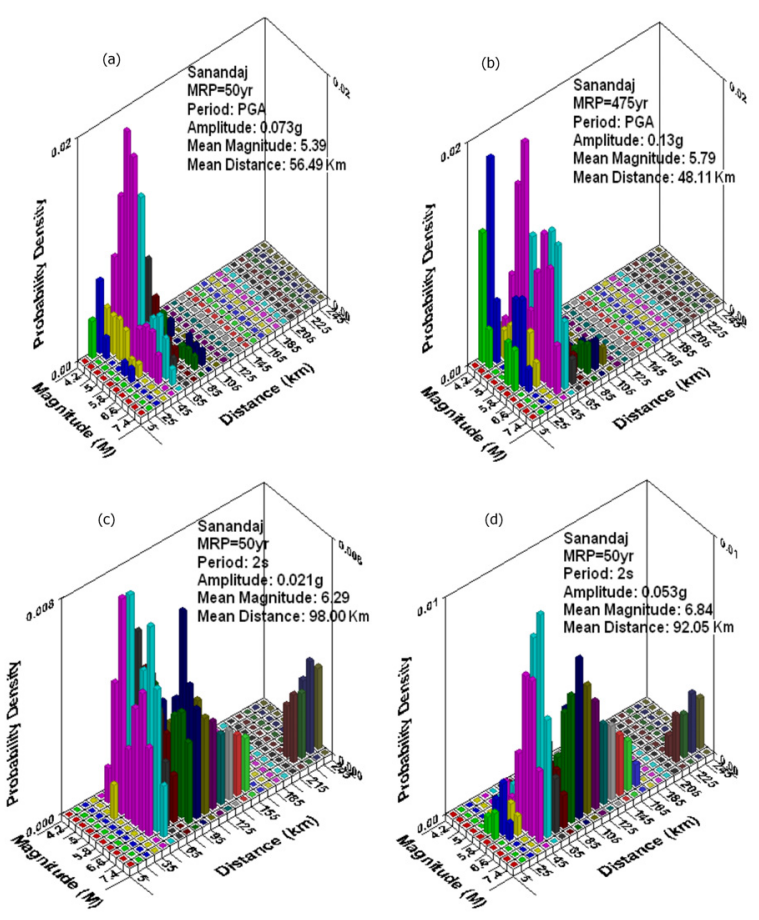

Figure 8. Disaggregated seismic hazard for a site in Sanandaj for $63 \%$ and $10 \%$ in 50 years probability of exceedances for PGA and $\mathrm{Sa}(0.2 \mathrm{~s})$. Bins of width 0.4 in magnitude, $10 \mathrm{~km}$ in distance, and 0.2 in $\varepsilon$ are used.
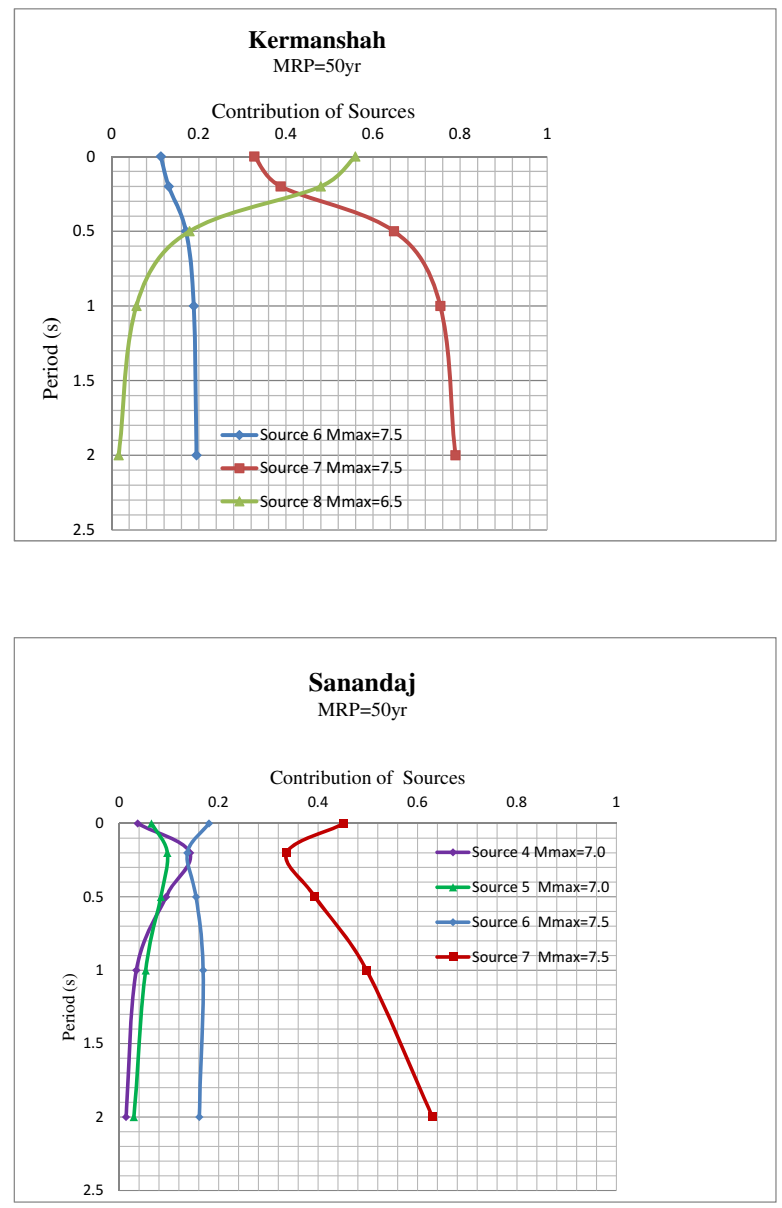

Figure 9. The most contributing seismic sources corresponding to 50-year return period in Kermanshah and Sanandaj. transparent to the end user of PSHA. As well as disaggregating the total hazard with respect to magnitude and distance one should also consider the contributions to the hazard that are made by various values of the deviation parameter in the GMPE $(\varepsilon)$. When the hazard disaggregation is performed in terms of the three variables, $\mathrm{M}, \mathrm{R}, \varepsilon$, one is able to get a complete picture of where the overall hazard comes from. An additional method that provides even greater clarity is the $4 \mathrm{D}$ disaggregation methodology proposed by Bazzurro and Cornell [1999] in which the positional contributions are also included by disaggregating the distance, further into latitude and longitude. In this study we performed $2 \mathrm{D}$ disaggregation in terms of M- $\mathrm{R}$ and, $1 \mathrm{D}$ disaggregation in terms of $\varepsilon$.

Usually, both mean and modal values of $M, R$ and $\varepsilon$ are reported for identifying the dominant event, because each of them has its advantages and disadvantages. The mean values $(\overline{\boldsymbol{M}}, \overline{\boldsymbol{R}})$ and $\bar{\varepsilon}$ are independent of the bin size, but they may correspond to a scenario that is not realistic, if there are two or more sources with a significant contribution to the hazard. The modal values represent the most likely event that may induce the specified acceleration level at the site. The values depend on the dimension of the bins [Bazzurro and Cornell 1999].

The seismic hazard results are disaggregated for Kermanshah and Sanandaj cities to help understand the relative contributions of the earthquake sources in terms of distance and magnitude. Bins of width 0.4 in magnitude, $10 \mathrm{~km}$ in distance, and 0.2 in $\varepsilon$ are used. Disaggregation results are generated by EZ-FRISK (version 7.43) computer program [Risk Engineering 2010], in terms of magnitude-distance, and epsilon separately.

For the sites of Kermanshah and Sanandaj, disaggregation of PGA and 0.2, 0.5, 1.0 and 2.0s spectral acceleration hazard is performed and mean and modal values are computed. Table 2 presents the variation of mean and modal values of, $R$, and $\varepsilon$ with spectral period for Kermanshah and Sanandaj.

The acceleration values disaggregated corresponds to return periods of 50 and 475 years. For an MRP of 50 yr, $\overline{\mathbf{M}}$ (mean) and $\mathbf{M}^{*}$ (modal) tend to increase slightly with period. The difference between mean and modal values of $\mathbf{R}$ for periods greater than $1.0 \mathrm{sec}$ indicates that more than one scenario contributes significantly to the site hazard for those spectral periods (Table 2). Similar observations can be made for an MRP of 475 years. Once again, examining the behavior of $\varepsilon$ indicates that both the mean and modal values increase as the MRP increases in Kermanshah. While for, Sanandaj, $\varepsilon$ does not show some specific trend. Moreover, for this latter site, it is clearly evident that the contribution from 
(a)

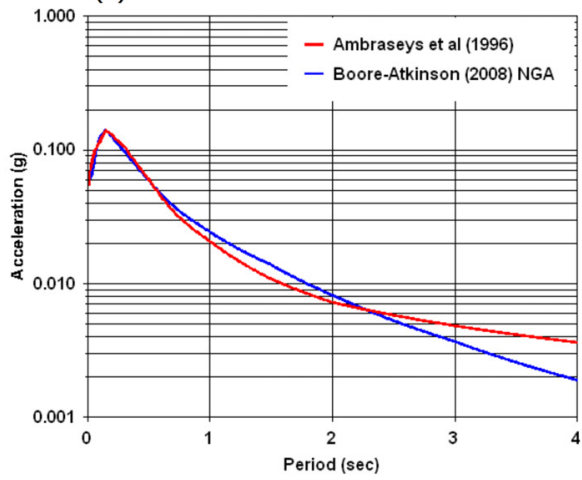

(c)

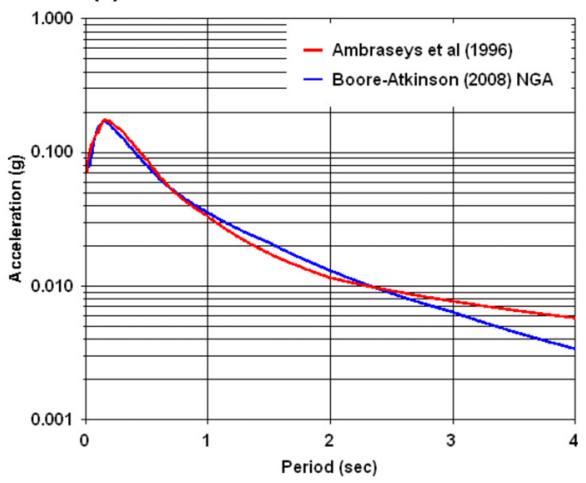

(b)

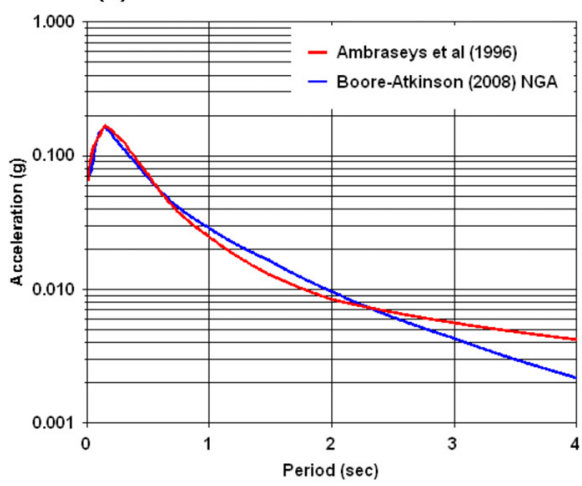

(d)

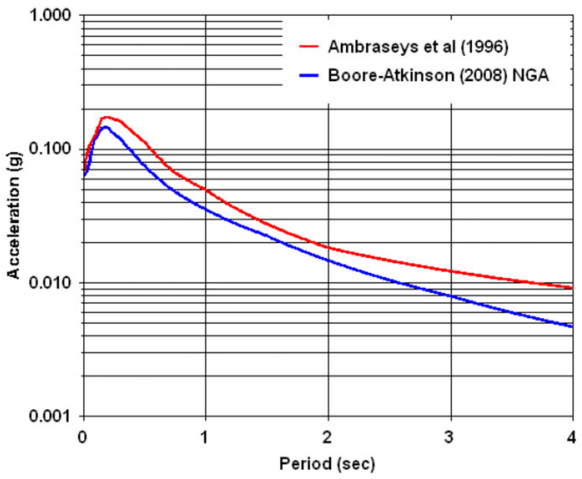

Figure 10. Spectral accelerations for earthquake scenarios in Kermanshah; (a) $\bar{M}=4.8$ at $\bar{R}=22 \mathrm{~km}$ for Sa (0.01 s) and MRP of 50-year, (b) $\bar{M}=5.7$ at $\bar{R}=42 \mathrm{~km}$ for Sa (0.01 s) and MRP of $475 \mathrm{yr}$, (c) $\bar{M}=4.9$ at $\bar{R}=21 \mathrm{~km}$ for Sa (2 s) and MRP of $50 \mathrm{yr}$, (d) $\bar{M}=6.1 \mathrm{at} \bar{R}=45 \mathrm{~km}$ for Sa (2 s) and MRP of 475-year.

(a)

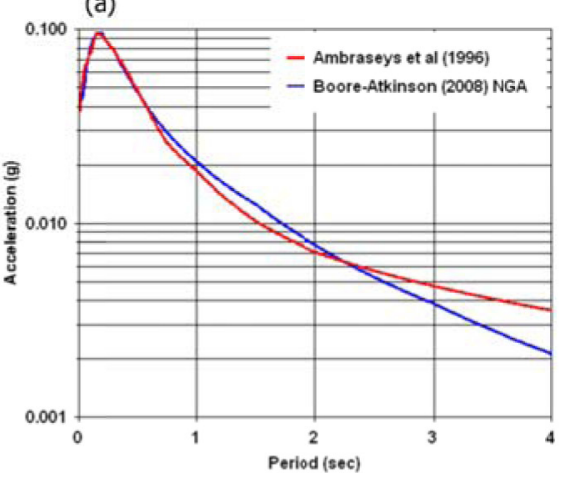

(c)

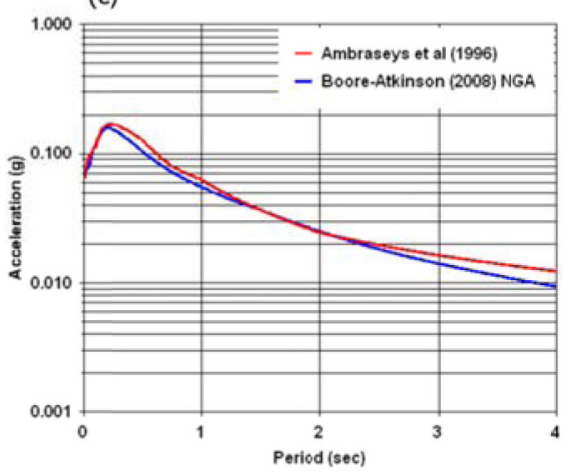

(b)

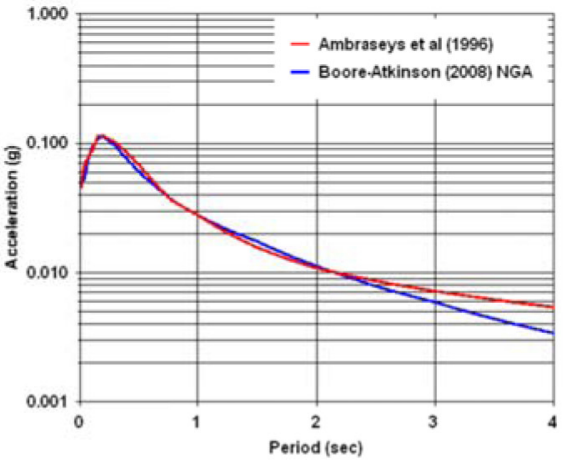

(d)

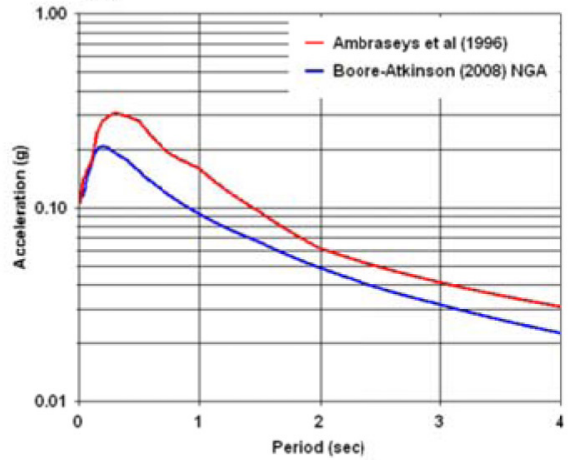

Figure 11. Spectral accelerations for earthquake scenarios in Sanandaj; (a) $\bar{M}=5.4$ at $\bar{R}=56 \mathrm{~km}$ for $\mathrm{S}_{\mathrm{a}}(0.01 \mathrm{~s})$ and $\mathrm{MRP}$ of 50 -year, (b) $\bar{M}=6.3$ at $\bar{R}=98 \mathrm{~km}$ for $\mathrm{S}_{\mathrm{a}}(0.01 \mathrm{~s})$ and MRP of 475 -year, (c) $\bar{M}=5.8$ at $\bar{R}=48 \mathrm{~km}$ for Sa $(2 \mathrm{~s})$ and MRP of 50 -year, (d) $\bar{M}=6.8$ at $\bar{R}=92 \mathrm{~km}$ for $\mathrm{S}_{\mathrm{a}}$ $(2 \mathrm{~s})$ and MRP of 475 -year. 
Kermanshah

Sanandaj

\begin{tabular}{|c|c|c|c|c|c|c|c|c|c|c|c|c|c|}
\hline \multirow{6}{*}{ 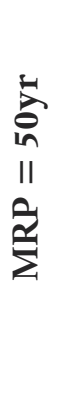 } & Period (s) & $\mathbf{M}^{*}$ & $\bar{M}$ & $R^{*}$ & $\bar{R}$ & $\varepsilon^{*}$ & $\bar{\varepsilon}$ & $\mathbf{M}^{*}$ & $\bar{M}$ & $R^{*}$ & $\bar{R}$ & $\varepsilon^{*}$ & $\bar{\varepsilon}$ \\
\hline & 0.01 & 5.0 & 4.8 & 25 & 22 & 1.3 & 1.4 & 5.4 & 5.4 & 45 & 56 & 2.1 & 1.7 \\
\hline & 0.2 & 5.0 & 4.9 & 25 & 23 & 1.5 & 1.6 & 5.4 & 5.4 & 45 & 59 & 2.1 & 1.9 \\
\hline & 0.5 & 5.4 & 5.2 & 25 & 27 & 1.5 & 1.6 & 5.4 & 5.8 & 45 & 76 & 2.1 & 1.6 \\
\hline & 1 & 5.4 & 5.4 & 25 & 34 & 1.5 & 1.5 & 5.4 & 6.2 & 55 & 87 & 0.5 & 1.2 \\
\hline & 2 & 5.4 & 5.7 & 25 & 42 & 1.7 & 1.5 & 6.6 & 6.3 & 55 & 98 & 0.3 & 1.2 \\
\hline \multirow{5}{*}{ 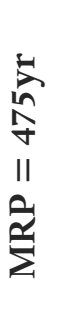 } & 0.01 & 5.0 & 4.9 & 25 & 21 & 1.7 & 2.0 & 5.4 & 5.8 & 45 & 48 & 1.1 & 1.7 \\
\hline & 0.2 & 5.4 & 5.0 & 25 & 22 & 1.9 & 2.1 & 5.4 & 5.8 & 45 & 52 & 2.7 & 2.0 \\
\hline & 0.5 & 5.4 & 5.3 & 25 & 26 & 1.9 & 2.1 & 7.0 & 6.4 & 55 & 71 & 1.3 & 1.7 \\
\hline & 1 & 5.4 & 5.8 & 25 & 35 & 1.9 & 2.0 & 7.4 & 6.8 & 55 & 82 & 1.1 & 1.4 \\
\hline & 2 & 5.4 & 6.1 & 25 & 45 & 4.1 & 4.0 & 7.4 & 6.8 & 55 & 92 & 1.1 & 1.5 \\
\hline
\end{tabular}

Table 2. Modal and mean values of magnitude, distance and epsilon for spectral periods in Kermanshah and Sanandaj, Sa (0.01s) represents the PGA.

stronger and distant events increases with spectral period. As an example, in the case of Sa $(0.5 \mathrm{sec}), \bar{\varepsilon}$ increases from 1.6 to 2.1 when the MRP changes from 50 to 475 years. Similarly, for the same spectral period, $\varepsilon^{*}$ changes from 1.5 to 1.9 .

In a same way, mean and modal values resulting from the disaggregation of the values of $5 \%$ damped spectral accelerations are calculated for Sanandaj (Table 2).Mean estimates of distance and magnitude are chosen, they are independent of bin sizes and locations and other binning details.

Scenario earthquakes in Kermanshah ranging from a magnitude $\overline{\boldsymbol{M}}=4.8$ at $\overline{\boldsymbol{R}}=22 \mathrm{~km}$ for $\mathrm{S}_{\mathrm{a}}(0.01 \mathrm{~s})$, to a magnitude $\overline{\boldsymbol{M}}=5.7$ at $\overline{\boldsymbol{R}}=42 \mathrm{~km}$ for $\mathrm{S}_{\mathrm{a}}(2.0 \mathrm{~s})$ has been determined to represent the relatively likely ground motion having a $63 \%$ chance of being exceeded in 50 years. For less probable, extreme ground motions with a $10 \%$ chance of being exceeded in 50 years, the selection might be a magnitude $\overline{\mathbf{M}}=4.9$ at $\overline{\boldsymbol{R}}=21 \mathrm{~km}$ for $\mathrm{S}_{\mathrm{a}}(0.01 \mathrm{~s})$ or a magnitude $\overline{\boldsymbol{M}}=6.1$ at $\bar{R}=45 \mathrm{~km}$ for $\mathrm{S}_{\mathrm{a}}$ $(2.0 \mathrm{~s})$ (Figure 7$)$. The vertical axis is probability density function vary between zero and one.

In a same way, seismic hazard has been disaggregated to determine scenario earthquakes for the two design levels for Sanandaj. Scenario earthquakes ranging from a magnitude $\bar{M}=5.4$ at $\overline{\boldsymbol{R}}=56 \mathrm{~km}$ for $\mathrm{S}_{\mathrm{a}}$ (0.01 s), to a magnitude $\overline{\boldsymbol{M}}=6.3$ at $\overline{\boldsymbol{R}}=98 \mathrm{~km}$ for $\mathrm{S}_{\mathrm{a}}(2.0$ $\mathrm{s})$ has been determined to represent the relatively likely ground motion having a $63 \%$ chance of being exceeded in 50 years in periods 0.01 and 2.0 seconds, respectively. For less probable, extreme ground motions with a $10 \%$ chance of being exceeded in 50 years, the selection might be a magnitude $\overline{\boldsymbol{M}}=5.8$ at
$\bar{R}=48 \mathrm{~km}$ for $\mathrm{S}_{\mathrm{a}}(0.01 \mathrm{~s})$ or a magnitude $\overline{\boldsymbol{M}}=6.8$ at $\overline{\boldsymbol{R}}=$ $92 \mathrm{~km}$ for $\mathrm{S}_{\mathrm{a}}(2.0 \mathrm{~s}$ ) (Figure 8).

The annual rate of exceedance for each source as the contribution of seismic sources are also examined for PGA and periods of $0.2,0.5,1.0$ and 2.0 seconds. Distribution of contribution level of seismic sources are shown with the most contributing seismic sources in Figure 9. Results of disaggregating the hazard into the individual source contributions shows the most contributing ones are sources 6, 7 and 8 corresponding to 50yr return period for the city of Kermanshah and sources 4, 5, 6 and 7 for the city of Sanandaj. The most contributing seismic source corresponding to 50yr return period is the source 7 with $M_{\max }=7.5$ in periods longer than $0.2 \mathrm{~s}$ in Kermanshah and in all periods in Sanandaj.

The controlling earthquakes are substituted in two attenuation relations developed in Ambraseys et al. [1996] and Boore and Atkinson [2008]. Figures 10 and 11 present the spectral shapes for scenario earthquakes in Kermanshah and Sanandaj using the above attenuation relations. One aspect associated with these values used to define dominant scenarios is that, when the M$\mathrm{R}$ is incorporated into the predictive equation, the identified scenarios might generate the target ground motion level, or will exceed the target ground motion level. It is important to note that the present disaggregation methodology, considers that the identified scenario, defined by the M-R, will exceed the target ground motion level. Harmsen and Frankel [2001] as well as, Bazzurro and Cornell [1999] have shown that for some regions in the western United States, the range of exceedance of the target ground motion level was small, with values ranging within $15-20 \%$ of the median value. 


\section{Results}

PGA and spectral acceleration values associated with MRPs of 50 and 475-yr in two cities of Kermanshah and Sanandaj are evaluated. In Kermanshah for an MRP of $50 \mathrm{yr}$, controlling earthquakes have magnitude range between 6 and 6.4. Events with magnitude ranging from 6.4 to 6.8 have the most contribution to the hazard for an MRP of $475 \mathrm{yr}$ and long periods, while the smaller magnitude ranging from 6 to 6.4 are dominant for shorter periods and PGA. Regarding disaggregation results, it could be concluded that events with most contribution to corresponding hazard levels are affected by the potential seismic sources number 6 and 7 .

The results indicate that, the PGA hazard for Kermanshah is controlled by the earthquake scenario of $\overline{\mathbf{M}}=4.9$ at $\overline{\boldsymbol{R}}=21 \mathrm{~km}$ which is the most critical to the seismic performance of the more vulnerable low rise buildings including soft-storey buildings. The alternative scenario of $\bar{M}=6.1$ at $\bar{R}=45 \mathrm{~km}$ which is relative to a longer period $(2.0 \mathrm{~s})$ can be used for the assessment of taller buildings. The PGA hazard for Sanandaj is controlled by the earthquake scenario of $\overline{\mathbf{M}}=5.8$ at $\bar{R}=48 \mathrm{~km}$, which is the most critical to the seismic performance of the more vulnerable low rise buildings including soft-storey buildings. The alternative scenario of $\overline{\boldsymbol{M}}=6.8$ at $\overline{\boldsymbol{R}}=92 \mathrm{~km}$ which is relative to a longer period $(2.0 \mathrm{~s})$ can be used for the assessment of taller buildings.

Relatively high values at Kermanshah in values of $\varepsilon^{*}$ and $\bar{\varepsilon}$ in Table 2 for MRP $=475 \mathrm{Y}$ and Period $=2 \mathrm{~s}$ is a consequence of many distant and local sources affecting the hazard additively.

Generally, the trend of the disaggregation results with spectral period ( $\mathrm{T}$ ) show that the mean rate of exceeding long-period spectral accelerations is controlled by earthquakes that are larger in size and farther from the site than those dominating the PGA and short-period spectral acceleration hazard. It is also observed that the larger the MRP, the greater the contribution from closer and higher magnitude events. Also, both the mean and modal values of $\varepsilon$ tend to increase with increasing MRP.

Acknowledgements. The authors gratefully thank the anonymous referees for the constructive comments, which significantly improved this article. The authors thank the Institute of Geophysics of the University of Tehran for the help it gave to this research.

\section{References}

Ambraseys, N.N., K.A. Simpson and J.J. Bommer (1996). Prediction of Horizontal Response Spectra in Europe, Earthquake Engineering and Structural Dynamics, 25, 371-400.

Ambraseys, N.N., J. Douglas, S.K. Sarma et al. (2005).
Equations for the estimation of strong ground motions from shallow crustal earthquakes using data from Europe and the Middle East: Vertical peak ground acceleration and spectral acceleration, Bulletin of Earthquake Engineering, 3, 55-73.

Anderson, J.G., and M.D., Trifunac (1978). Uniform Risk Functionals for Characterization of Strong Earthquake Ground Motion, Bull. Seismol. Soc. Am., 68, 205-218.

Barani, S., D. Spallarossa and B. Bazzurro (2009). Disaggregation of Probabilistic Ground-Motion Hazard in Italy, Bull. Seismol. Soc. Am., 99, 2638-2661.

Bazzurro, P., and C.A. Cornell (1999). Disaggregation of seismic hazard, Bull. Seismol. Soc. Am., 89, 501520.

Berberian, M. (1995). Master "blind” thrust faults hidden under the Zagros folds: Active basement tectonics and surface morphotectonics, Tectonophysics, 241, 193-224.

Boore, D.M., and G.M. Atkinson (2008). Ground-motion prediction equations for the average horizontal component of PGA, PGV, and $5 \%$-damped PSA at spectral periods between $0.01 \mathrm{~s}$ and $10.0 \mathrm{~s}$, Earthq. Spectra, 24, 99-138.

Bozorgnia, Y., and Bertero, V.V. (2004). Earthquake engineering, from engineering seismology to performance-based engineering, CRC press, $976 \mathrm{pp}$.

Campbell, K.W., and Y. Bozorgnia (2008). NGA ground motion model for the geometric mean horizontal component of PGA, PGV, PGD and 5\% damped linear elastic response spectra for periods ranging from 0.01 to $10 \mathrm{~s}$, Earthq. Spectra, 24, 139-171.

Campos Costa, A., M.L. Sousa, A. Carvalho, J.B. Serra and E.C. Carvalho (2002). Regional seismic risk scenarios based on hazard deaggregation, In: Proceedings of the 12th European conference on earthquake engineering, London, UK, Paper 470 (CD Rom).

Chapman, M.C. (1995). A probabilistic approach to ground motion selection for engineering design, Bull. Seismol. Soc. Am., 85, 937-942.

Chioccarelli, E., and I. Iervolino (2013). Near-source seismic hazard and design scenarios, Earthquake Engineering and Structural Dynamics, 42 (4), 603-622.

Chiou, B., and R.R. Youngs (2008). An NGA model for the average horizontal component of peak ground motion and response spectra, Earthq. Spectra, 24, 173-216.

Cornell, C.A. (1968). Engineering Seismic Risk Analysis, Bull. Seismol. Soc. Am., 58, 1583-1606.

Cramer, C.H., and M.D. Petersen (1996). Predominant seismic source distance and magnitude maps for Los Angeles, Orange and Ventura counties, California, Bull. Seismol. Soc. Am., 86, 1645-1649. 
Frankel, A.D., C. Mueller, T. Barnhard, D.M. Perkins, E. Leyendecker, N. Dickman et al. (1996). National seismic hazard maps; documentation June 1996, U.S. Geological Survey Open-File Report, 96-532; http:/ / pubs.er.usgs.gov/usgspubs/ofr/ ofr96532, (accessed September 27, 2007).

Frankel, A.D., C. Mueller, T. Barnhard, E. Leyendecker, R.L. Wesson, S.C. Harmsen et al. (2000). USGS national seismic hazard maps, Earthq. Spectra, 16, 1-19.

Harmsen, S., D. Perkins and A.D. Frankel (1999). Deaggregation of probabilistic ground motions in the Central and Eastern United States, Bull. Seismol. Soc. Am., 89, 1-13.

Harmsen, S., and A.D. Frankel (2001). Geographic deaggregation of seismic hazard in the United States, Bull. Seismol. Soc. Am., 91, 13-26.

Harmsen, S., A.D. Frankel and M.D. Petersen (2003). Deaggregation of U.S. Seismic Hazard Sources: the 2002 Update, U.S. Geological Survey, Open-File Report 2003-03-440.

Knuepfer, P.L.K. (1989). Implications of the characteristics of end-points of historical surface fault segmentation and controls of rupture initiation and termination, Open-File Rep./U.S. Geol. Surv. 89315, pp. 193-228.

McGuire, R.K. (1995). Probabilistic seismic hazard analysis and design earthquakes: closing the loop, Bull. Seismol. Soc. Am., 85, 1275-1284.

Mirzaei, N., M.T. Gao and Y.T. Chen (1999). Delineation of potential seismic sources for seismic zoning of Iran, J. Seismol., 3, 17-30.

Montilla, J.A., C.L. Casado and J.H. Romero (2002). Deaggregation in magnitude, distance, and azimuth in the South and West of the Iberian Peninsula, Bull. Seismol. Soc. Am., 92, 2177-2185.

Power, M., B. Chiou, N. Abrahamson, Y. Bozorgnia, T. Shantz and C. Roblee (2008). An overview of the NGA project, Earthq. Spectra, 24, 3-22.

Reiter, L. (1990), Earthquake Hazard Analysis: Issues and Insights, Columbia University Press, New York. ISBN 0-231- 06534-5.

Risk Engineering (2010). Ez-Frisk user manual (version 7.43), Risk Engineering, Inc., Golden, Colorado, USA.

Sabetta, F. (2013). Seismic hazard and design earthquakes for the central archaeological area of Rome, Bull. Earthquake Eng.; doi:10.1007/s10518-0139427-6.

Shabani, E., and N. Mirzaei (2007). Probabilistic seismic hazard assessment of the Kermanshah-Sanandaj region of Western Iran, earthq. Spectra, 23, 175-197.

Shi, Z., J. Yan and M. Gao (1992). Research on the principles and methodology of seismic zonation: Re- sults of the trials in North China, Acta Seismol. Sinica, 5, 305-314.

Shoja-Taheri, J., S. Naserieh and G. Hadi (2010). A test of the applicability of NGA models to the strong ground-motion data in the Iranian Plateau, J. Earthq. Eng., 14, 278-292.

Sousa, M.L., and A.C. Costa (2009). Ground motion scenarios consistent with probabilistic seismic hazard disaggregation analysis, Application to Mainland Portugal, Bull. of Earthquake Engin., 7 (1), 127-147.

Tchalenko, J.S., and J. Braud (1974). Seismicity and structure of the Zagros-Iran: The Main Recent Fault between $33^{\circ}$ and $35^{\circ} \mathrm{N}$, Philos. Trans. R. Soc. London, A227, 1-25.

Wellman, H.W. (1966). Active wrench faults of Iran, Afghanistan, and Pakistan, Geologische Rundschau, 55, 716-735.

Wells, D.L., and K.J. Coppersmith (1994). New empirical relationships among magnitude, rupture length, rupture width, rupture area, and surface displacement, Bull. Seismol. Soc. Am., 84, 974-1002.

Yan, J. (1993). Principles and methods to determine spatial distribution function, In: Proceedings PRC/USSR Workshop on Geodynamics and Seismic Risk Assessment, Beijing, China, 159-167.

Ye, H., G. Chen and Q. Zhou (1995). Study on the intraplate potential seismic sources, In: Proc. Fifth International Conf. Seismic Zonation, Nice, France, 2, 1424-1430.

\footnotetext{
${ }^{\star}$ Corresponding author: Elham Shabani, University of Tehran, Earth Physics Department, Institute of Geophysics, Tehran, Iran; email: eshabani@ut.ac.ir.

(C) 2013 by the Istituto Nazionale di Geofisica e Vulcanologia. All rights reserved.
} 